\title{
REPRESENTAÇÕES SOBRE A RELAÇÃO ENTRE EDUCAÇÃO E MODERNIZAÇÃO EM GUARAPUAVA-PR ENTRE 1930 E 1960.
}

\author{
Mari Lucia do Amaral \\ Graduada em Pedagogia \\ Unicentro, Guarapuava-PR \\ Carlos Herold Junior \\ Professor Adjunto do Departamento de Pedagogia \\ Unicentro, Guarapuava-PR
}

\section{RESUMO:}

O objetivo do texto é analisar de que forma se relacionaram diferentes representações sobre a relação entre modernização sócio-econômica e educação na cidade de Guarapuava no período de 1930 a 1960. Utilizando-se de jornais publicados na cidade durante o período, o texto se encontra dividido em duas partes: na primeira parte trata-se, conceitual e historicamente, da modernização no contexto mais amplo do capitalismo internacional e nacional. Na segunda, são estudados como os impetos modernizantes eram vistos e relacionados à educação em Guarapuava entre 1930 e 1960. Como conclusão, observa-se que apesar dos problemas estruturais da educação guarapuavana, as diferentes representações em torno da modernização da cidade atribuem à educação grande valor, colocando-a ora como um indício de um determinado progresso concebido como existente, ora vendo-a como parâmetro a ser acompanhado por setores da vida econômica e social do município.

Palavras-chave: Educação, Modernização, Guarapuava, história da educação.

\section{REPRESENTATIONS ABOUT THE RELATIONSHIP BETWEEN EDUCATION AND MODERNIZATION IN GUARAPUAVA-PR BETWEEN 1930 AND 1960.}

\begin{abstract}
:
The aim of this paper is to examine the relationship among representations of socioeconomic modernization and education in Guarapuava during the period from 1930 to 1960. Using newspaper published in the city, the text is divided into two parts: in the first part is studied, conceptually and historically, the modernization in the broader context of international capitalism and national levels. In the second, we study how the modernizing impulses were seen and related to education in Guarapuava between 1930 and 1960. In conclusion, we observed that despite the structural problems of education of Guarapuava, several representations about the modernization of the city attach great value to education, placing it either as an indication of a specific progress conceived as existing, or sometimes seeing it as parameter to be accompanied by sectors of economic and social council. Key-words: Education, Modernization, Guarapuava, History of education.
\end{abstract}

\section{Introdução}

Guarapuava está localizada à 250 quilometros de Curitiba, na região Centro-oeste do Paraná. Tendo sido alçada ao status de cidade em 1871, forma um dos municípios mais antigos do Estado. Em 1924, o inspetor Cesar Prieto Martinez, ao realizar inspeções escolares na cidade, antes de apresentar os problemas que ele observou na instrução 
pública do município, descreve a cidade como aquela "[...] que maravilhou os excursionistas de antanho e que despertou cobiças justificáveis [...]", enfatizando que Guarapuava era "a sede do maior município paranaense, maior talvez que a Belgica, um Estado dentro de outro Estado" (MARTINEZ, 1924, p. 90).

Essas observações tem como objetivo pontuar que o recorte espacial desta análise histórica dá conta de um contexto importante para história educacional do Paraná, mas que, aos mesmo tempo, como observado em outro estudo (HEROLD JR, 2007), não tem merecido atenção sistemática dos analistas.

Para impulsionar qualitativa e quantitativamente a pesquisa sobre a história educacional da cidade, desenvolvemos entre 2007 e 2009 o projeto "Escolarização e instituições educacionais em Guarapuava-PR entre 1860 e 1960", No estudo, constatamos que, sobretudo, entre 1930 e 1960, a questão educacional ganha maior destaque, ocupando um tempo relevante de autoridades e de educadores. De forma geral, qualquer assunto sobre os rumos educacionais, fosse ele pedagógico ou político, girava em torno da importância que a educação teria, ou deveria ter, no desenvolvimento e modernização da cidade. Considerando essa constatação, advinda do levantamento que fizemos na pesquisa acima mencionada, elegemos como objetivo deste trabalho investigar as relações entre as representações sobre educação e as representações sobre a modernização em Guarapuava entre 1930 e 1960.

O alcance do objetivo proposto se deu sustentado, do ponto de vista documental, em jornais publicados no período em foco. Mesmo que outras tipologias de documentos tenham sido também usadas, foram os jornais que nos deram condições de verificar como, cotidianamente, a educação tornou-se uma pauta recorrente nos embates políticos locais e nas lutas para fazer acontecerem os diferentes processos modernizadores da economia, da política e da sociedade em questão. Além disso, eles se constituíram em indícios para se entender as dificuldades experimentadas para que esses processos tivessem lugar. Nesse sentido, são importantes as considerações de Schelbauer e Araújo (2005), que ao organizarem uma coletânea que reúne estudos sobre a história da educação escritos utilizando periódicos, afirmam que "As pulsões contemporâneas em torno da pesquisa histórico-educacional têm eleito também a imprensa como fonte e objeto seus."(SCHELBAUER; ARAÚJO, 2005, p.5) Afinal, "Se a educação é uma prática social que se estrutura a partir do que é veiculado pela cultura, a imprensa tem seu lugar na educação dos homens em sociedade" (SCHELBAUER; ARAÚJO, 2005, p.5).

Outra consideração importante, do ponto de vista da estrutura metodológica deste estudo, é a ênfase naquilo que Chartier (2002) chama de representação. Ela é fundante, pois, guia as reflexões de modo a evitar que elas, ao lidarem com as fontes, simplesmente endossem "[...] totalmente o que encontram, aproximando-se de seu objeto de conhecimento sem antes filtrá-lo através de crítica mais rigorosa" (CAMARGO apud DE LUCA, 2006, p.117). Essa "crítica mais rigorosa", acreditamos, pode ser aprimorada se considerarmos que nossa análise tem como objeto a:

[...] compreensão das formas e dos motivos - ou, por outras palavras, das representações do mundo social - que, à revelia dos actores sociais, traduzem as suas posições e interesses objectivamente confrontados e que, paralelamente, descrevem a sociedade tal como pensam que ela é, ou como gostaria que fosse (CHARTIER, 2002, p.19). 
Para realizar esses cuidados metodológicos o texto está dividido em duas partes. $\mathrm{Na}$ primeira, discutimos a modernização como problema histórico e teórico, focalizando-a, nos marcos do amplo processo de formação do capitalismo, buscando direcionar essas ideias para o contexto nacional a partir de 1930. Na segunda parte, debruçamo-nos, especificamente, sobre as relações entre modernização e educação na cidade de Guarapuava, investigando a partir dos jornais, como diferentes representações se formam, complementam-se e, às vezes, contradizem-se ao expressarem as transformações que aconteciam e as que não aconteciam nos âmbitos sociais, políticos, econômicos e educacionais.

\section{Crise e modernização como problemas do capital: impactos na educação brasileira.}

$\mathrm{Na}$ tentativa de fazer uma correlação entre educação e modernização, a conceituação de modernização apresentada por Outhwaite e Bottomore (1996, p.477-478) é elucidativa. Dentre as variáveis presentes nos processos de modernização, enfatizam os autores que modernização é o:

Processo de mudança econômica, política, social e cultural que ocorre em países subdesenvolvidos na medida em que se direcionam para padrões mais avançados e complexos de organização social e política. Foi minuciosamente estudado e definido nas teorias sociológicas norteamericanas do pós-guerra que partem da referência implícita ou explicita a uma dicotomia entre dois tipos ideais: a sociedade tradicional (que em algumas versões também pode ser chamada de "rural", "atrasada" ou "subdesenvolvida") e a sociedade moderna (ou "urbana", "desenvolvida", "industrial"). [...] A idéia é que todas as sociedades seguem um caminho histórico semelhante, de crescente diferenciação e complexidade e de um tipo polar a outro. (OUTHWAITE; BOTTOMORE, 1996, p.477-478).

Assumindo essa definição em uma perspectiva histórica, notamos que modernização, tornar moderno ou realizar modernizações, são processos que ganharam grande relevância nos marcos da construção do capitalismo, desde o século XVI. Nesse sentido, nos séculos XIX e XX verificamos a continuidade de um amplo processo de transformação global, que tocou todas as dimensões da sociedade, desde as políticas, culturais e pessoais, possuindo uma grande relação com os desafios colocados para a consolidação da nova organização produtiva. Estamos diante da formação de um modelo em que, no dizer de Marx e Engels (1987, p.106), “[...] todas as novas relações tornam-se antiquadas, antes mesmo de se consolidarem. Tudo que era sólido e estável evapora-se no ar [...]". Isso se dá, pois “[...] A burguesia só pode existir com a condição de revolucionar incessantemente os instrumentos de produção e, por conseguinte, as relações de produção [...]" (MARX e ENGELS, 1987, p.105).

Araújo (2007, p.87) verifica que a ideia de progresso sedimenta-se como consequência dos debates levantados no século XVIII e XIX, adquirindo uma conotação central no bojo das concepções iluministas. Nessa perspectiva, à humanidade caberia definir a direção daquilo que conduz ao progresso, afirmando-o como contínuo, sem retrocesso. A educação apareceria como o instrumento destinado ao desenvolvimento igual das faculdades para uma vida social que possibilitasse uma marcha ascendente e inexorável rumo ao moderno, que passou a ser visto como condição sine qua non da justiça, da fraternidade e da liberdade. A educação, nesse contexto de expansão das "águas geladas do cálculo" (MARX e ENGELS, 1987, p.105), é reconhecida como a força propulsora capaz 
de construir uma sociedade justa e moderna, baseada nos valores e aspirações partilhados pelo Iluminismo: o progresso tornou-se concebido como resultante da aplicação da razão e da ciência, para a qual a educação popular, não sem divergências entre os teóricos do liberalismo, tornou-se elemento de grande importância. Por conta disso, pensar a história da educação, sobretudo, a partir do contexto de expansão dos sistemas nacionais de ensino no século XIX, é relacioná-la com os incontáveis esforços de modernização. Podemos dizer que, no campo especificamente pedagógico, modernizar, lutar contra o que era visto como ultrapassado, elitista e ineficiente, transformou-se em uma das constituintes dos discursos pedagógicos.

Hobsbawn (1995) mostra que no século XX, paralelamente à modernização e ao progresso, foram muito recorrentes os discursos sobre o desenvolvimento $\mathrm{e}$ subdesenvolvimento. Desenvolvimento indicaria a conquista do progresso econômico e social por meio da superação do estágio de subdesenvolvimento em países que passam a ser chamados de países "em desenvolvimento". O progresso econômico (capitalista) passa a ser, ideologicamente, visto como uma condição necessária para a efetivação de um progresso social, representado pela satisfação das necessidades básicas como nutrição, saúde, habitação, liberdades civis, participação política e o acesso universal à educação.

No Brasil, essas discussões sobre a modernização, desenvolvimento e aplicação da razão e da ciência nos rumos políticos sociais, deu vida à história política do país desde o contexto da indepedência, passando por todo o século XIX e chegando às primeiras décadas da República. Com essas considerações a frente, observamos que no Brasil o que se convencionou chamar Revolução de 30 foi um processo no qual um jogo complexo de rupturas e continuidades políticas e econômicas em relação à velha ordem social oligárquica, aconteceram, todas objetivando dar espaço à "modernidade".

Xavier (1990) chama atenção para o fato de a ordem econômica-social consolidada no Brasil da época ter sido um resultado possível de um avanço capitalista sustentado sobre as estruturas tradicionais, e que acabou perpetuando uma consciência nacional que se via como dependente. O processo brasileiro de industrialização/modernização concretizou, gradualmente, uma acomodação ao novo papel que a reorganização da economia mundial impunha à economia nacional. Isso gerou importantes bases para que a educação brasileira fosse tocada pelas peculiariedades da modernização dependente do Brasil:

No mesmo processo, foi dispensando crescentemente e cada vez mais explicitamente a colaboração de uma renovação cultural e educacional que favorecesse e fortalecesse um desenvolvimento econômico autosustentado e soberano. A modernização rápida e eficiente que a economia mundial exigia e as classes dominantes nacionais aspiravam para vencer os obstáculos gerados pelo esgotamento das formas tradicionais de dominação do capital, pulando etapas e com isso poupando o amadurecimento da consciência nacional rumo a um projeto próprio, não gerou apenas um descompasso entre o progresso material alcançado e os mecanismos institucionais responsáveis pela socialização desse progresso. Gerou ainda um descompasso irreversível entre o avanço do sistema de produção e os mecanismos institucionais, de natureza cultural e educacional, indispensáveis à sustentação e ao incremento de um avanço autônomo (XAVIER, 1990, p.145).

Nagel (1992) endossa essas ideias afirmando que a história da educação brasileira pode ser melhor entendida se seus momentos de grande agitação de ideias e reformas forem vistos à luz das grandes crises do capitalismo que, em última instância, acabam por 
apoiar-se nos discursos modernizantes para fazer face às suas contradições. A autora, além do final do século XIX e dos anos a partir de 1970, nota que em 1930 "idéias renovadoras sobre o sistema educativo invadem a sociedade"(1992, p. 03), imprimindo aos debates educacionais ímpetos que buscavam:

[...] a criação de novos serviços para melhor direcionar o ensino, para melhor programar politicamente a educação, para melhor difundir a escola, para implantar matérias ou disciplinas novas no currículos acadêmicos considerados retrógrados, ou para melhor a didática da instrução. (NAGEL, 1992, p. 03).

Em síntese, a crise mundial de 1929 funcionou como uma força imediata para mudanças no Brasil, visto que seria necessário um projeto que redimensionasse o papel do país na divisão internacional do trabalho. Pode-se dizer que o processo de redefinição do projeto econômico brasileiro induziu a sua redefinição política que, por sua vez, influenciou o projeto de reorganização do sistema educacional. Isso ensejou que variadas dimensões sociais, culturais e econômicas se fornecessem oscilações, contradições e estímulos que acicataram os choques e os acompanhamentos entre os processos de desenvolvimento locais e globais de transformação da sociedade brasileira, fazendo-se sentir, também no contexto paranaense e, ainda mais especificamente, na realidade de Guarapuava.

\section{As representações pela modernização educacional no contexto guarapuavano}

Guarapuava nos anos 30 vivia uma crise econômica decorrente da crise do tropeirismo e que se faria presente até o final da década. A atividade tropeira na cidade estava em declínio desde o início do século XX em conseqüência da melhoria dos rebanhos de São Paulo e a construção e prolongamento de estradas de ferro que substituiram o transporte, até então, feito em tropas de mulas. Isso agravou o isolamento da região de Guarapuava. (SILVA, 1997). A crise mundial de 1929, só veio a piorar a situação da cidade levando os fazendeiros a venderem suas terras a preços irrisórios ou arrendá-las, o que, de forma geral, acarretou uma queda no nível de consumo e no padrão de vida da população. (TEMBIL, 2007, p. 89).

A vida econômica da cidade ganharia novo impulso a partir de 1940 com os madeireiros que se instalaram na região, estimulados pelo fato de Guarapuava deter uma das maiores reservas florestais do Paraná (TEMBIL, 2007). A presença, então, desse novo segmento iria modificar, substancialmente, as relações de poder e a dinâmica social da cidade. $\mathrm{O}$ advento da indústria da madeira acabou por acelerar transformações no sentido de uma urbanização da cidade, na proporção, inclusive, em que forçou o incremento das vias de transporte para a sua circulação.

É no bojo desse processo de retomada de crescimento e de modernização da cidade que queremos focalizar as transformações e as problemáticas relativas à educação: Como a educação se desenvolvia no contexto acima mencionado? Quais eram as pressões da sociedade em relação à importância das estruturas educacionais?

Uma primeira constatação a ser feita é que a partir da 1930 a questão educacional começa a ser veiculada de maneira mais intensa nos jornais da cidade. A instrução passa a ser vista requisito básico na evolução da sociedade guarapuavana. Em um artigo publicado no jornal "O Combate", de julho de 1931 percebe-se que a educação é colocada como base dos processos modernizantes almejados : 
As revoluções, que não são revoltas, mas, factores de evolução dos povos, cumpre, si não quizerem ver fracassados, no futuro, os seus esforços e trabalhos pela renovação social e política do paiz, occuparem-se intelligente e carinhosamente, da educação do povo. [...] A instrucção é a maior força productiva na vida civilisadora moderna [...]. (O COMBATE, 05/07/1931, p.2).

Entretanto, colocar a educação como balisa modernizadora implicava a luta contra uma situação concebida como desfavorável à realização das benesses educacionais. No final do mesmo artigo, a educação aparece como um direito negado, mas já há algum pleiteado. O articulista relaciona a possibilidade de mudança com o clima "revolucionário" instaurado a partir de 1930, assumindo que, enfim, as reivindicações populares por escolas seriam atendidas:

\begin{abstract}
Esse estado de cousas, além de prejudicar immensamente as crianças, provoca descontentamento nos povoados prejudicados e, ainda, semeia a desconfiança e até antipathia, contra o Governo da Revolução. Tal se dá porque o caboclo e o colono que jamais recebem qualquer benefício dos governos pedem e se julgam com direito, ao menos, a um auxílio: escolas para os seus filhos. O governo do Paraná não pode nem deve desilludir, assim este pobre povo que da Revolução não pede senão: Escolas, Escolas! (O COMBATE, 05/07/1931, p.2). (Sem grifos no original).
\end{abstract}

Essas solicitações encontravam uma realidade que, dificilmente, se alterava. Isso pode ser visto nos números que começaram a ser colhidos e publicados de forma cada vez mais frequente, dando conta dos problemas educacionais que existiam na cidade.

Em 1934, o prefeito Arlindo Martins Ribeiro, não escondia seu otimismo com as possibilidades de maior arrecadação, ventiladas com a promulgação da nova constiuição. No seu entendimento, a nova carta dava aos municípios melhores condições de aumentarem suas arrecadações, que seriam revertidas, entre outras coisas, para a "construção das casas escolares e fornecimento de mobiliário"(RIBEIRO, 1934, p.14). Porém, já em 1936, o mesmo prefeito, ao relatar a situação da educação pública em Guarapuava à interventoria do Estado, apresenta dados colhidos em 1932, pelo inspetor escolar da cidade, Miguel Bohomoletz: "Das 40 escolas existentes, 14 possuem casas próprias, 9 alugadas e 18 cedidas pelos seus proprietários, sem pagamento de aluguel" (Bohomoletz apud Ribeiro, 1934, p.21). Dois anos depois, a situação não mudara. Ao final do relatório de 1936, o prefeito retoma ( e transcreve) as seguintes conclusões do relatório de 1932:

Sómente 9 escolas teem situação estável possuindo casas especialmente construidas; 21 escolas dependem da permanência do professor que a construiu, da vontade de moradores locais ou de individuos isolados, que alugam ou emprestam a casa. Não é ececional o caso, quando uma desinteligencia entre o professor e o proprietario da casa, tem como conseqüência a retirada, da escola do lugar. É necessário, pois, empregar todos os esforços para modificar essa situação anormal...(BOHOMOLETZ apud RIBEIRO, 1934, p.23) (Sem grifos no original) 
Amarilio Rezende de Oliveira (FOLHA DO OESTE, 14/03/1937), também criticava o descaso do governo estadual com a educação da cidade, enfatizando que os governos municipais, dentre eles o de Guarapuava, estavam fazendo muito pelo assunto, considerando que esse esforço, ainda, não era o suficiente. Em outro artigo, (FOLHA DO OESTE, 09/05/1937), o professor crítica a Câmara de Vereadores, enfatizando a necessidade de mais escolas para as crianças que moravam no interior. Notamos que em cada âmbito administrativo, bem como na relação entre os poderes municipais e estaduais, a vontade de mudanças era um traço presente em todos aqueles que faziam uso da palavra impressa, imputando ao "outro"(à outra esfera administrativa, ao inimigo político, ao setor econômico concorrente) a responsabilidade pela situação.

Antonio Lustosa de Oliveira (FOLHA DO OESTE, 23/03/1941) uniu-se ao grande número de pessoas que elegeram os problemas educacionais como questão, buscando causas e culpados. Ele demonstrava que entre 1930 e 1940, o número de escolas mantidas pela prefeitura municipal de Guarapuava diminuíra. Essa situação fortalecia a consciência de que a situação da educação guarapuavana apresentava problemas que eram sentidos de forma mais branda em outras regiões do Paraná. Lustosa de Oliveira, como prefeito de Guarapuava em 1945, ao encaminhar um relatório sobre vários aspectos do município e, especialmente, ao falar sobre a instrução publica, constata que, mesmo consumindo 33\% da receita municipal e mantendo 25 escolas municipais, "[...] Para se atender o mínimo das necessidades relativas à instrução primária, teremos que elevar ao dobro o número de escolas municipais [...]"(1945, p.08). Outro índice que endossa a situação problemática de Guarapuava no âmbito educacional paranaense foram as análises de Erasmo Pilotto (1946, p.72), que ao fazer um estudo sobre a educação do Estado, concluia que Guarapuava detinha o pior índice de aprovações $(25,5 \%)$.

Guarapuava, em 1952, considerando os dados apresentados pelo inspetor escolar Rivadávia Saraiva (1952), possuía 3.264 alunos nas 114 escolas (estaduais, municipais e particulares) existentes. Sem esquecermos que no censo populacional brasileiro de 1950 havia no município 55.690 pessoas com mais de cinco anos de idade, sendo que apenas 24.776 eram alfabetizados (FERREIRA, 1959, p.238), é possível verificar que os problemas educacionais já levantados no início da década 30 persistiram, tornando-se partes integrantes do contexto educacional do município.

Yalo Cabral narra um fato através do qual também é possível entrever a maneira complexa com que "as águas geladas do cálculo" (MARX e ENGELS, 1987) se relacionam com as dimensões culturais de um contexto, sobretudo, se essas dimensões estiverem direcionadas às classes populares. Cabral inicia suas ponderações verificando que após alguns anos vivendo em outra cidade, o retorno a Guarapuava possibilitou visualizar "seu progresso em vários setores". Para o articulista, a vivacidade dessa impressão não causou surpresa, afinal ele considerava Guarapuava como a "Canaan do Paraná".

Por outro lado, Cabral critica o fato de "progresso espiritual" não ter acompanhado o "progresso material". A constatação do "atraso espiritual" em meio ao progresso econômico da cidade foi feita tendo por base o não funcionamento da biblioteca municipal. Afirmou sua surpresa: afinal, mesmo com três projetos aprovados na Câmara Municipal e uma "unânime boa vontade" da população, o que existia de concreto era "apenas um prédio fechado". É observado, também, que a criação legal da biblioteca remontava a 17 de Dezembro de 1948 e que várias autoridades e intelectuais da cidade já tinham demonstrado a vontade de fazer doações de livros. Por conta disso, conclui que a "modernização espiritual", concretizada no funcionamento da biblioteca e do museu, deveria acontecer : 
Consideramos enfim, uma necessidade inadiável o museu e a biblioteca de Guarapuava. Devemos zelar hoje pelo amanhã de nossos filhos e isto implica em incutir-lhes amor pelas nossas coisas do passado, admiração pelos vultos de nossa terra, ao par da cultura e do saber. (FOLHA DO OESTE, 18/03/1956).

Por outro lado, ao continuarmos a buscar indícios para o estudo da história da educação guarapuavana nos jornais, encontramos, paralelamente à desconsideração do "progresso espiritual" e aos dados acima apresentados que objetivam alertar para uma situação educacional e cultural plena de dificuldades, outro tipo de representação sobre o desenvolvimento educacional da cidade.

Observamos que uma das questões que mais faziam as escolas e a sua importância serem assuntos de discussão pública e cotidiana eram as diferentes maneiras como o mundo escolar sinalizava a modernização da cidade ou, também, como as escolas e as práticas educacionais eram vistas como importantes estímulos e justificativas para que as transformações ocorressem nos mais variados setores da vida municipal. Dessa maneira, vale deixar claro que a constatação acima se baseava em representações que possuíam, assim, dois registros: em alguns momentos, os analistas viam em Guarapuava uma cidade em franco processo de desenvolvimento e transformação, característica essa que tinha na velocidade das mudanças nas escolas que iam surgindo e no número de alunos que cresciam, um importante indício. Ao lado dessa maneira de analisar as mudanças da cidade, encontramos aqueles que defendiam que Guarapuava ainda carecia de incrementos estruturais importantes, e que esses melhoramentos possuíam como justificativa e exemplo o desenvolvimento do mundo escolar visto como "moderno".

Focando o primeiro registro, Rodrigues de Oliveira constata um "surto de progresso" que atingia não somente Guarapuava, mas o Estado do Paraná como um todo. Mesmo sem criticar o contexto político de Manoel Ribas, visto como "sadio", defende que as transformações que constatava se deviam a uma "inteligencia bem dirigida", vista como apanágio da "fase lupiônica". Ao listar a maneira como o "plano bem orientado" estava se materializando, afirma:

Em qualquer cidade ou vila, eis que se erguem predios para escolas. Eis que uma estrada rasga uma mata e corta uma campina... Aqui está $a$ maior preocupação de nosso grande Governo-:estradas escolas. Dentro desse binômio, seu governo tem sido grandioso inigualavel...escolas, para plasmar o espirito, polir o cérebro do futuro brasileiro; estradas, para o escoamento de nosso produto, para a invasão dos trabalhadores nas matas ferteis de nosso "hinterland", no salvaguardamento de nosso futuro.(FOLHA DO OESTE, 26/02/1950, p.1). (Sem grifos no original).

O articulista elabora seu raciocínio sobre a modernização do Estado sustentada na construção de escolas e estradas. Assim, ao abordar o contexto especificamente guarapuavano, também ressalta as "magníficas construções do belissimo grupo escolar, uma Escola para Trabalhadores Rurais, uma Escola Normal Regional e mais uma centena de Escolas Isoladas."(FOLHA DO OESTE, 26/02/1950, p.1).

Em 1957, Rodrigues de Oliveira, ao verificar que o clima eleitoral já colocava a oposição na necessidade de se utilizar da "velha arma" de tudo criticar, mais uma vez defende os governos de Lupion e Joaquim Prestes, considerando que suas atitudes eram condizentes com as necessidades modernizantes do Estado e da cidade. Por conta deles, é observado que Guarapuava havia entrado na "senda do progresso". As "provas" oferecidas 
pelo articulista, caracterizam-se, novamente, pela tonalidade pedagógica. Ele menciona o funcionamento da Escola de Trabalhadores Rurais, o incremento e a modernização da Escola Normal, bem como "melhoramentos materiais" proporcionados ao Ginásio Estadual. Interessante observar na estrutura do artigo que esses indícios pedagógicos da modernização da cidade são colocados lado a lado, por exemplo, com o calçamento de algumas partes (centrais) da cidade.

Em outro artigo cujo objetivo era exaltar a administração de Joaquim Prestes, notamos que a base dessa propaganda era afirmar que a "terra das araucárias prossegue em sua marcha vitoriosa na senda do progresso e da grandeza"(FOLHA DO OESTE, 31/03/1957, p.1) Para endossar essa marcha e a relação da mesma com as alardeadas virtudes do governo municipal, o articulista faz uma descrição de Guarapuava que deixa clara sua vontade de mostrar a cidade como moderna: "Cidade limpa,[...] possue belos jardins e ruas bem calçadas, luz elétrica, cinemas, comércio sólido e de grande expressão, indústrias etc. Desde o ano passado que possúe telefones [...]"(FOLHA DO OESTE, 31/03/1956, p.1). Afirma, também, que um dos traços mais marcantes da modernização de Guarapuava, ao lado das "centenas de madeireiras", era a construção de "estradas, escolas, urbanismo etc" que assegurariam à Guarapuava um "futuro radiante e promissor".

Mais uma vez Rodrigues de Oliveira constata, em outro artigo, um "surto de progresso" que, no seu entendimento, fez com que Guarapuava passasse por uma "verdadeira metamorfose". Ele analisa que esse surto, por "imperativos da própria civilização", ainda estava em andamento, fazendo com que a antiga ideia de que Guarapuava seria apenas um "recanto longínquo", "onde as feras dominavam e as estradas feitas por cascos de Burros" (FOLHA DO OESTE, 16/07/1957, p.1), ficasse, definitavamente, para trás.

Notamos que existia a representação que relacionava a "chegada da civilização" com a fertilidade do solo, sendo esse traço o grande distintivo de Guarapuava. Por conta disso, o articulista conclui que com a "descoberta de Guarapuava" por parte dos "coestaduanos distantes", era necessário incrementar as reivindicações. A intenção de Rodrigues de Oliveira era mostrar que um "campo de aviação" já poderia ser construído em Guarapuava, considerando que a "civilização" já estava materializada em outras áreas: "É verdade, que já temos estrada doe (sic) ferro, telefône, boas escolas, ruas calçadas etc. Mas isto não basta."(FOLHA DO OESTE, 16/06/1957). (sem grifos no original).

Jamardo Oliveira narra uma situação por ele vivida em Curitiba que é elucidadora das representações conflitantes existentes em torno da cidade de Guarapuava das transformações pelas quais ela passava. Ele relata a interpelação de uma senhora que perguntara se em Guarapuava existiam muitos índios e se eles atacavam a cidade. A questão causou grande indignação em Oliveira, que acabou por afirmar que a ignorância das pessoas em torno da vida em Guarapuava era grande: "Era o fulano que perguntava se nós ainda usávamos lampião ou candieiro; era sicrano perguntando se as boiadas atravessavam a cidade com destino às capitais; era beltrano querendo saber se dava para saír à noite, sem perigo de morte.”(FOLHA DO OESTE, 03/08/1958, p.1).

Oliveira tenta mostrar que as ideias que davam conta de um grande atraso da cidade eram equivocadas, afinal, por outro lado, relatava que sempre ouvia pessoas que por Guarapuava passavam e que se surpreendiam com o seu "verdadeiro aspecto de cidade". No momento de fazer frente à essas impressões, endossando a modernidade guarapuavana, Jamardo de Oliveira expressa de forma muito contunde o lugar que a vida escolar da cidade tinha ao balisar a superação das concepções que "em absoluto, fazem justiça ao nosso modus vivendi”. Era preciso mostrar que "[...] aqui já contávamos com uma estação de rádio, jornais semanários, ginásio, Escola Normal, Escola de Comércio, calçamento em 
quase todo o centro, telefones a(sic)algumas coisas mais que êles nem de longe imaginam." (FOLHA DO OESTE, 03/08/1958, p.1).(Sem grifos no original).

Ao lado desse conjunto de ideias que relacionava o progresso e a modernização da cidade, entre outras coisas, com uma certa pujança educacional, notamos que havia outra forma de relacionar educação e modernização em Guarapuava.

Paula Junior inicia suas reflexões afirmando que Guarapuava passava pelo o que ele também chamava de "surto de progresso". Observamos em suas reflexões algumas hesitações ao pontuar a particularidade do processo em Guarapuava. Afinal, mesmo assumindo que Guarapuava tinha sido "[...] incluida entre as cidades progressistas do Brasil", também defende que "esse fenomeno não se registrou apenas entre nós, mas em todas as cidades do nosso Estado, que, qual São Paulo dos velhos tempos, sentiram uma evolução rápida, inesperada.”(FOLHA DO OESTE, 03/06/1956, p.1).

Ele raciocina que o "surto do progresso" encejou um grande conjunto de problemas. Se nos cento e quarenta anos passados, Guarapuava possuia uma "vida praticamente estabilizada", "sem maiores progressos", a não ser aqueles advindos do "aumento natural de sua população", a situação em que vivia apresentava outro cenário: "Teve assim, Guarapuava, nos ultimos anos, um consideravel aumento de população e, em face disso, um progresso nunca então registrado em fase tão rápida."(FOLHA DO OESTE, 03/06/1956, p.1)

Observamos que há uma defesa de uma certa naturalidade e generalidade do processo, ao mesmo temo em que há uma tentativa de afirmar uma especial pujança do ritmo modernizante de Guarapuava. É considerado que a sempre benvinda modernização estava causando problemas estruturais na cidade e que, consequentemente, as pressões por soluções se dirigiam as esferas estaduais e municipais da administração. Em uma tentativa explícita de amenizar essas pressões, o articulista argumenta:

Não temos água, não temos força eletrica suficiente, não temos estradas em condições, não temos hoteis e tudo mais. É essa, no entretanto (sic), uma fase transitória, natural, e já verificada em todas as cidades - pois bem o sabemos não é mesmo possível, a um governo Municipal ou Estadual, acompanhar a iniciativa particulares. (FOLHA DO OESTE, 03/06/1956, p.1)

Nesse sentido, é interessante observar que o "surto de modernização" de Guarapuava estava concretizado, no entender de Paula Junior, no incremento população originado pela vinda do imigrantes, que buscavam o "solo exuberante" das "terras de Guairacá". Dessa maneira, o surto modernizante fazia-se sentir muito mais pela pressão populacional e pelos atributos da terra, do que pela realização material da infra-estrutura municipal no que diz respeito à agua, luz, estradas, hotéis, calçamento, entre outras.

Assinando um editorial como João do Planalto, o deputado Lustosa de Oliveira acreditava que Guarapuava, diferentemente do ele via ocorrer nos nos anos 40, não estava recebendo a atenção devida do governo do Estado, que acabava desconsidernado que o município era de "incontestável importância econômica no conceito dos municípios paranaenses". Além disso, o deputado afirmava que de Guarapuava com "seu povo laborioso", oferecia importante ajuda para o Paraná "[...] situar-se na federação brasileira como a unidade estadual de maior desenvolvimento em todos os sectores de progresso."(FOLHA DO OESTE, 19/04/1959, p.1).

Essas ideias dão conta, assim, de que o progresso era um traços marcantes da cidade e do Estado do Paraná e que somente não eram mais estimulados por questões políticas. Exaltando o fato do "grande aeroporto" já ter sido construído e estar 
possibilidanto a ligação da "[...] nossa progressista e encantadora cidade com a Capital do Estado e demais centros do País", o redator observa que, por outro lado, problemas básicos relacionados à eletricidade, água e esgoto ainda afligirem, sobremaneira, os habitantes do municípios. Para mostrar a incongruência dessa falta de progresso em um município "tão progressista", João do Planalto lista os marcos colocavam em evidência os avanços da cidade, lista essa que dá à consolidação do mundo escolar um grande valor:

Esses dois inadiáveis empreendimentos (Rede de água e esgoto; usina hidro-elétrica) são essenciais para a aceleração da expansão de Guarapuava, cuja rede municipal, conta, atualmente, com cerca de quinze mil habitantes, detentora de estabelecimentos de ensino primário $e$ secundário, nos quais perto de mil e quinhentos estudantes dedicam-se ao aperfeiçoamento intelectual. Além disso, a nossa cidade conta com importantes estabelecimentos industriais e comerciais, com uma unidade do Exército Nacional e tantos outros fatores de progresso, que se tornam manietados pela falta de Fôrça e Luz, e do serviço de saneamento desta trepidante metrópole opulenta região do Oeste Paranaense. (FOLHA DO OESTE, 19/04/1959, p.1). (Sem grifos no original).

\section{Considerações finais}

Nos jornais publicados em Guarapuava no período em tela, pudemos verificar que havia representações diferentes sobre o estado em que estavam estruturas educacionais da cidade, quando por exemplo, ao lado de tentativas de por a público dados que endossavam os problemas educacionais da cidade, encontramos articulistas que viam na educação indícios de uma "metamorfose", assumida como realidade, das estruturas sócioeconômicas de Guarapuava.

Ao mesmo tempo, foi possível perceber que as transformações da vida urbana, também não foram encaradas de forma isenta de discordâncias. Afinal, como explicar, de um lado, a crença em um "surto de modernização" e, de outro, o fato de a modernização ser concebida com um "surto de população" que, no final das contas, reclamavam por saneamento, energia elétrica, maior dinamismo econômico, vistos como ausentes. Interessante foi constatar que nessas últimas representações, eram as estruturas educacionais assumidas como parâmetros, como bases, como exemplos e como fomentadoras de necessidades que tornavam urgentes a modernização da cidade.

Com isso, não pretendemos negar, ingenuamente, os variados processos de transformação econômica e educacional da cidade, mas, também, não desconsideramos que a visibilidade desses processos só existe por meio de um processo de análise e questionamentos agudos às fontes primárias que, até agora, encontramos em nossas pesquisas. Por conta dessa observação, notamos que ao lado dos resultados levantados por este trabalho, acreditamos que igualmente importantes são os questionamentos que ele pretende estimular sobre outras facetas da história educacional de Guarapuava.

Por fim, ao colocarmos como objetivo investigar as variadas representações sobre a educação em Guarapuava e sua relação com as transformações que ocorriam ou que eram vistas como necessárias por aqueles que davam vida às lutas sociais, políticas e econômicas, assumimos a consideração de que a especificidade do contexto guarapuavano pode ser útil para pensarmos uma questão fundante para aqueles que, hoje, estudam as possibilidades e os limites da educação na construção de novas malhas societárias. Essa importância realiza-se por lançar aos analistas da educação condições para se verificar de que maneira avanços e retrocessos sócio-econômicos impingem ao mundo educacional pautas que extrapolam a agenda, especificamente, pedagógica; do mesmo modo, essa 
relevância pode se tornar realidade por demonstrar uma certa permeabilidade das pautas econòmicas, culturais e políticas às questões que dizem respeito, especificamente, à consolidação e aos problemas do mundo escolar. Tudo isso endossa a necessidade de se tomar Guarapuava (bem como outras cidades) como recortes empíricos específicos mas que se mostram como fundamentais para o entendimento tanto das vicissitudes quanto das generalidades da história da educação paranaense e brasileira.

\section{Referências}

ARAUJO, J. C. O progresso e a Educação: de sua genealogia às expressões no Triangulo Mineiro In: SCHELBAUER, A. R.; ARAUJO, J. C. (orgs). História da educação pela imprensa. Campinas, SP: Alínea, 2007.

CHARTIER, R. A História Cultural: entre práticas e representações. Rio de Janeiro: Bertrand Brasil, 2002.

DE LUCA, T. R. História dos, nos e por meio dos periódico. In: PINSKI, C. B. (Org.). Fontes históricas. 2.ed. São Paulo: Contexto, 2006. p.111-154.

HEROLD JUNIOR, C. Escolarização e instituições educacionais em Guarapuava: lançando as bases para um programa de pesquisa em história da educação, Revista HISTEDBR On-line, v. 28, p. 214-223, 2007.

HOBSBAWM, E. Era dos Extremos: o breve século XX: 1914-1991. São Paulo: Companhia das Letras, 1995.

MARX, K.; ENGELS, F. Cartas filosóficas e $\mathbf{O}$ manifesto do partido comunista de 1848. São Paulo: Editora Moraes, 1987.

NAGEL, L. H. Crise da sociedade e da educação. In: Apontamentos, Maringá, n.09, 1992, p.1-13.

OUTHWAITE, W.; BOTTOMORE, T. (Orgs.) Dicionário do pensamento social do século XX. Rio de Janeiro: Jorge Zahar Editor, 1996.

SCHELBAUER, A. R.; ARAÚJO, J. C. S. (Orgs.). História da educação pela imprensa. Campinas, SP: Editora Alínea, 2007.

SILVA, J. M. Processos econômico-sociais regionais e seus impactos sobre a estrutura urbana de Guarapuava. Revista de história regional. 1997. Disponível em

http://www.revistas.uepg.br/index.php?journal=rhr\&page=article\&op=view\&path $\% 5 \mathrm{~B} \% 5$ $\mathrm{D}=60 \&$ path\%5B\%5D=27. Acesso em: 28 out. 2009.

TEMBIL, M. Em busca da cidade moderna: Guarapuava... recompondo histórias, tecendo memórias. Guarapuava:Unicentro, 2007.

XAVIER, M. E. S. P. Capitalismo e escola no Brasil: a constituição do liberalismo em ideologia educacional e as reformas do ensino (1931-1961). Campinas, SP: Papirus, 1990.

\section{Fontes primárias}

FERREIRA, J. P. Enciclopédia dos municípios brasileiros. Rio de Janeiro: IBGE, 1959. Disponível em: http://biblioteca.ibge.gov.br Acesso em 31/12/2008.

FOLHA DO OESTE. Estradas e Escolas. Guarapuava, 26/02/1950, n.63, p.1. 
FOLHA DO OESTE. Museu e Bilioteca Pública "Visconde de Guarapuava". Guarapuava, 18/03/1956, n. 120, p.5.

FOLHA DO OESTE. Problemas de Guarapuava. Guarapuava, 03/07/1956, n.130, p.1.

FOLHA DO OESTE. Guarapuava. Guarapuava, 31/03/1957, n.169, p.1.

FOLHA DO OESTE. Comentários. Guarapuava, 05/05/1957, n.174, p.1.

FOLHA DO OESTE. Comentários. Guarapuava, 16/07/1957, n.180, p.1.

FOLHA DO OESTE. Índios em Guarapuava. Guarapuava,03/08/1958, n.235, p.1.

FOLHA DO OESTE. Necessidades de Nossa Terra. Guarapuava, 19/04/1959, n.267 p.1.

FOLHA DO OESTE. Escolas: mais escolas para nosso município. Guarapuava, 14/03/1937, n.3, p.1.

FOLHA DO OESTE. Por Guarapuava. Guarapuava, 09/05/1937, n.11 p.1.

FOLHA DO OESTE. A instrução pública no municipio. Guarapuava, 23/03/1941, n. 60, p.1.

MARTINEZ, C. P. Relatório apresentado ao Exmo. Sr. Dr. Secretario Geral de Estado. Curityba: Typ. da Penitenciaria do Estado, 1924.

OLIVEIRA, A. L. de. Relatório 1944-1945 apresentado ao Exmo Snr. Interventor Manoel Ribas. Curitiba: Editora Guaíra Limitada, 1945.

PILOTTO, E. A educação no Paraná (Síntese sobre o ensino público elementar e médio). Rio de Janeiro: MEC-INEP,1946.

RIBEIRO, A. M. Relatorio apresentado ao Exmo. Sr. Manoél Ribas. Guarapuava: São Paulo Editora Ltda, 1934.

SARAIVA, R. Correspondência ao Prefeito Municipal de Guarapuava. 18/02/1952. Centro de Documentação e Memória da Unicentro, 1952, Caixa 78.

${ }^{\mathrm{i}} \mathrm{O}$ projeto contou com apoio do CNPq na forma de auxílio à pesquisa.

Artigo recebido em: 20/04/2010

Aprovado em: 27/06/2010 